\title{
Kiwifruit Seedlings 'Watt' and 'Hayward' Physiological Response to Salt Stress
}

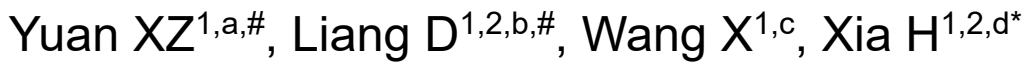 \\ ${ }^{1}$ College of Horticulture, Sichuan Agricultural University, Chengdu 611130, China; \\ 2 Institute of Pomology and Olericulture, Sichuan Agricultural University, Chengdu 611130, China \\ a1723065255@qq.com, b756141959@qq.com, c347434587@qq.com, d381683619@qq.com
}

${ }^{\#}$ Co-first author, *Corresponding author

Key words: kiwifruit; salt stress; salt tolerance

Abstract: Two cultivars kiwifruit seedlings 'Watt' and 'Hayward' were used as materials to compare their physiological response to $100 \mathrm{mmol} \cdot \mathrm{L}^{-1} \mathrm{NaCl}$ stress. The results showed that under salt stress, the chlorophyll content, relative electrical conductivity and malonaldehyde (MDA) content in both cultivars leaves were all showed an upward trend, while the soluble protein increased at earlier stage, but fall at later stage. During the whole process, the relative conductance and MDA content in 'Watt' were significantly lower than these in 'Hayward', indicating that 'Watt' had stronger tolerance to salt stress than 'Hayward'.

\section{Introduction}

Soil salinization is a global problem. In China, The salinized soil accounted for $1 / 4$ of the existing cultivated land, and about $80 \%$ of them have not yet been developed and utilized, which has become one of the biggest limiting factors for of agriculture development ${ }^{[1]}$.

Kiwifruits, known as the "King of $\mathrm{V}_{\mathrm{C}}$ ", are rich in trace elements, amino acids, vitamin $\mathrm{C}\left(\mathrm{V}_{\mathrm{C}}\right)^{[2]}$. 'Watt' is a species of Actinidia eriantha Benth, which has strong growth potential and resistance, wide adaptability with high stable yield and good market prospect [3]. 'Hayward' belonged to Actinidia chinensis var deliciosa, is one of the major cultivars in word and China ${ }^{[4]}$. It was called "King of Fruit" due to its delicate flesh, rich aroma, sweet and refreshing taste, rich nutritional value and good medicinal value ${ }^{[5]}$. The increasing consumption of kiwifruit in China has greatly stimulated the the development of kiwifruit cultivation and production. In this study, two varieties of kiwifruit seedlings were used as materials to compare the salt tolerance under salt stress, which will provide theoretical basis for the production of kiwifruit on the saline-alkali soil and the selection of rootstocks.

\section{Materials and Methods}

Material Preparation. The seeds were collected from ripen kiwifruit, and kept dry. In January, a smooth and full kiwifruit was selected and sterilized by soaking in 5\% sodium hypochlorite solution for 5 minutes, and then stored at $4{ }^{\circ} \mathrm{C}$ for 2 months. After poikilothermic treatment at $25{ }^{\circ} \mathrm{C} / 4{ }^{\circ} \mathrm{C}(8$ $\mathrm{h} / 16 \mathrm{~h})$ for 2 weeks, seeds were placed in a $25 \pm 1{ }^{\circ} \mathrm{C}(12 \mathrm{~h} / 12 \mathrm{~h})$ incubator for germination. The germinated seeds were sown in seedling disks with mixed soil (peat soil: vermiculite: perlite $=3: 1: 1$ ). At three true leaf stages, every 3 seedlings were transplanted into a $23 \mathrm{~cm} \times 18 \mathrm{~cm}$ pot placed in the culturing chamber with temperature at $25 \pm 1{ }^{\circ} \mathrm{C}$, and light $12 \mathrm{~h} / 12 \mathrm{~h} .1 / 2$ Hoagland nutrient solution is applied every 2 days.

Plant treatment. When the seedlings grew to 8 true leaves, uniform seedlings were selected and transferred into a $40 \mathrm{~cm} \times 35 \mathrm{~cm} \times 15 \mathrm{~cm}$ water culture box with1/2 Hoagland nutrient solution for one week pre-cultivation, then treated with $100 \mathrm{mmol} \cdot \mathrm{L}^{-1} \mathrm{NaCl} .2$ boxes for each repeat, and repeated 3 times. samples were collected from the 3rd to 6th true leaves at 9:00 am on the 0th, 1st, 2nd, 3rd, and 4th day of $\mathrm{NaCl}$ treatment, then frozen in liquid nitrogen and stored at $-80^{\circ} \mathrm{C}$ for late determination. 
Indicator measurement. The content of chlorophyll was determined with the method of Gao ${ }^{[6]}$ with slight improvement; relative conductance, soluble protein content, MDA content were measured with reference to Li's Method ${ }^{[7]}$.

Data analysis. Excel 2010 was used for data processing and charting, SPSS 20.0 was used for significance analysis by one-way variance and Duncan method.

\section{Results and analysis}

Chlorophyll content changes under salt stress. As shown in Figure 1, during the salt stress process, the chlorophyll content of 'Watt' increased significant and reached to maximum at $2 \mathrm{~d}$ with about $2.5 \mathrm{~mol} \cdot \mathrm{L}^{-1}$, then fell back down to $0 \mathrm{~d}$ level at $4 \mathrm{~d}$. Otherwise, the chlorophyll content in 'Hayward' shown different pattern, which kept persistent increase with the prolongation of stress time, and reached the maximum $\left(3.52 \mathrm{~mol} \cdot \mathrm{L}^{-1}\right)$ at $4 \mathrm{~d}$, which was $38.35 \%$ higher than $0 \mathrm{~d}$. Overall, the chlorophyll content in 'Watt' was consistently significantly lower than that in 'Hayward'.

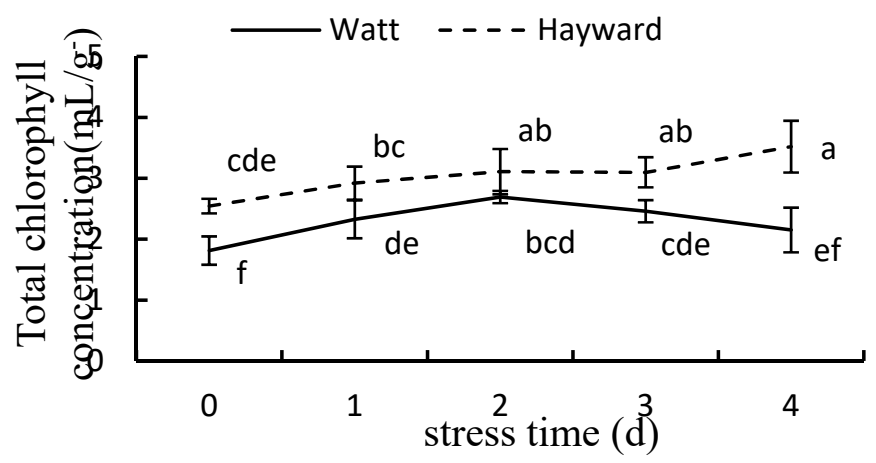

Figure 1 Effect of $\mathrm{NaCl}$ stress on total chlorophyll content in leaves of kiwifruit seedlings.

Note: The different letters in the figure indicated significant differences at the $5 \%$ level, the same below.

Membrane permeability under salt stress. Salt stress destroyed membrane stability and caused increase the permeability of the cell membrane of the plant, resulting electrolyte leakage and the electrical conductivity increase. In this study (Figure 2), the relative conductivities of the leaves of two kiwifruit seedlings were very low at $0 \mathrm{~d}$ with $18 \%$ ('Watt') and $21 \%$ ('Hayward'), respectively. With the increase of salt stress time, the electrical conductivity continued to increase. At $4 \mathrm{~d}$, the electrical conductivity increased by 1.46 times and 2.22 times than at $0 \mathrm{~d}$. Overall, the conductivity of 'Watt' has was significantly lower than that of 'Hayward'. The result indicated 'Watt' had stronger salt tolerance than 'Hayward' under the $100 \mathrm{mmol} \cdot \mathrm{L}^{-1} \mathrm{NaCl}$ stress.

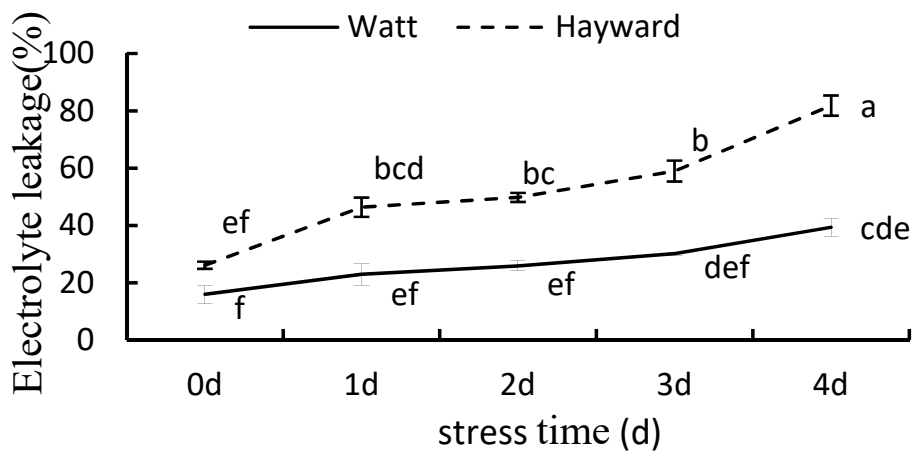

Figure 2 Relative conductivity in leaves of kiwifruit seedlings under $\mathrm{NaCl}$ stress

Soluble protein content under salt stress. Soluble proteins in plant cells are important osmotic adjustment substance, which are induced by salt stress to maintain normal physiological activity. As shown in Fig. 3, under salt stress, the soluble protein content of two kiwifruit seedling leaves increased with time and reached a maximum at the $3 \mathrm{~d}$, which were $6.43 \mathrm{mg} \cdot \mathrm{g}^{-1}$ ('Watt') and 6.86 $\mathrm{mg} \cdot \mathrm{g}^{-1}$ ('Hayward'), compared with $0 \mathrm{~d}$ significantly increased by $19.35 \%$ and $43.87 \%$, but slightly 
decreased at $4 \mathrm{~d}$. In the early stage of salt stress $(0-2 \mathrm{~d})$, the soluble protein content of leaves of 'Watt' seedlings was higher than that of 'Hayward', however, it was lower at the later time (2-4 d), but the difference was not significant.

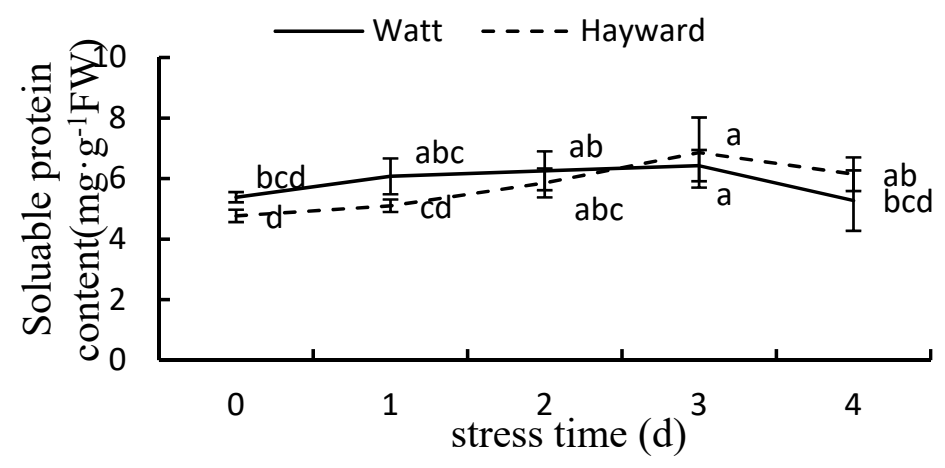

Figure. 3 Effect of $\mathrm{NaCl}$ treatment on soluble protein content in leaves of kiwifruit seedlings.

Malondialdehyde content under salt stress. Malondialdehyde (MDA) is a membrane lipid peroxidation product, and its content can be used as the basis for determining the degree of membrane damage. In this study (Fig. 4), the MDA content of the leaves of two kiwifruit cultivars at the $0 \mathrm{~d}$ was at the lowest value, both being less than $0.0061 \mathrm{nmg} \cdot \mathrm{g}^{-1}$. With the prolongation of stress time, the MDA content showed a double-peak rising trend, reached the first peak at $1 \mathrm{~d}$, significantly higher than $0 \mathrm{~d}$, decreased or remained unchanged from $2 \mathrm{~d}$ to $3 \mathrm{~d}$, the maximum value of $4 \mathrm{~d}$ is 1.47 times ('Watt') and 1.10 times ('Hayward') for $0 \mathrm{~d}$.

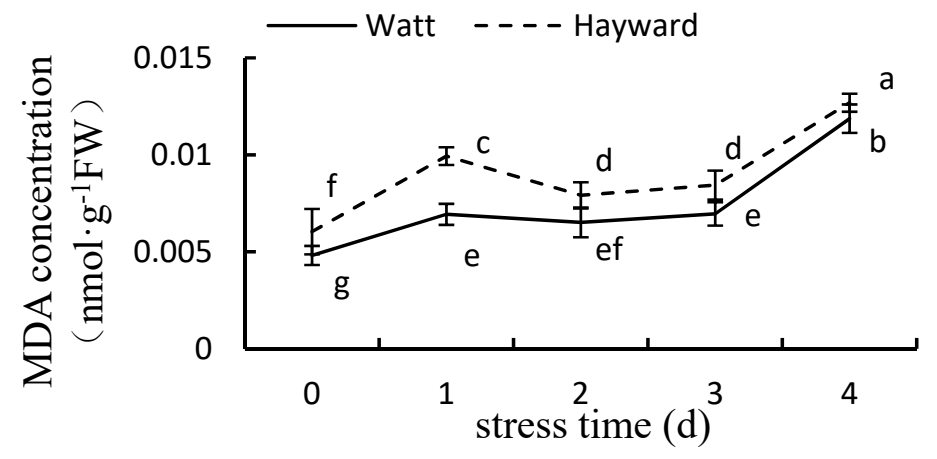

Figure.4 Effect of $\mathrm{NaCl}$ treatment on MDA content in seedling leaves.

\section{Discussion}

The amount of chlorophyll does not only determine the photosynthetic efficiency of the plant, but also sometimes measures the salt tolerance of the plant. In this experiment, during the period of stress, the two kiwifruit varieties showed an overall increase in the chlorophyll content of the seedling leaves. This may be due to the fact that under the salt concentration $\left(100 \mathrm{mmol} \cdot \mathrm{L}^{-1} \mathrm{NaCl}\right)$, 'Watt' and 'Hayward' The self-regulatory ability of the seedling leaves is strong, and in order to maintain their normal level of photosynthesis, the synthesis of chlorophyll is accelerated, thereby improving its salt tolerance.

The relative conductivity is an index that directly reflects the permeability of the plasma membrane of the plant cells, and the level of the relative conductivity reflects the ability of the plant cells to adapt to the stability of the intracellular environment and the changes of the extracellular environment. The relative conductivity is at a lower level and the smaller the rise, the stronger its salt tolerance. Soluble protein is one of the important osmotic adjustment substances in plant cells. The increase of its content can maintain stability and resist salt stress by regulating the intracellular and external water potential of plant cells. The MDA content of membrane lipid peroxidation product can indirectly reflect the damage situation of the membrane system. Under the same stress intensity, the relative conductivity increases, the soluble protein content decreases, the more MDA accumulates, the greater the damage, and the weaker the salt tolerance. 
In summary, under the stress of $100 \mathrm{mmol} \cdot \mathrm{L}^{-1} \mathrm{NaCl}$, 'Watt' had parent stronger salt tolerance than 'Hayward'.

\section{Acknowledgements}

This work was financially supported by the Sichuan Technical Supports Foundation (2016NZ0105) and Training Programs of Innovation for Undergraduates in Sichuan (201610626057).

\section{References}

[1] Munns R, Tester M. Mechanisms of salinity tolerance[J]. Annual Review of Plant Biology, 2008, 59(1): 651-651.

[2] Chen D, Yang JS. Soil Saline Environment and Nutrient Management[J]. Advances in Posozoology, 1995, 23(5): 7-13.

[3] Zhang HQ, Xie M, Xiao JP, et al. Study on the fruit development characteristics of kiwifruit 'Hua Te'[J]. JOURNAL OF FRUIT SCIENCE, 2015, 32(2): 238-246.

[4] Lin X. Effects of Different Plant Growth Regulators on the Survival Rate of Walnut Kiwifruit[J]. Journal of Agricultural Sciences and Technology, 2017(11): 68-69.

[5] Zhu WZ. Kiwifruit rookie - Walter [J]. Northwest Horticulture (fruit trees), 2015(2): 51-52.

[6] Gao JF. Plant Physiology Technology[M]. World Book Publishing House, 2000:387-384.

[7] Li HS. Physiological and Biochemical Experimental Principles and Techniques[M]. Higher Education Press, 2000. 